\title{
Sentence Recognition Performance in Visual-Only and Auditory-Visual Conditions by Normal and Hearing Impaired Adults
}

\author{
Jonghyun Kwak ${ }^{\mathrm{a}}$, Jaehee Choi ${ }^{\mathrm{a}}$, Hyunsook Jang ${ }^{\mathrm{b}}$ \\ ${ }^{a}$ Department of Speech Pathology and Audiology, Graduate College, Hallym University, Chuncheon, Korea \\ ${ }^{b}$ Division of Speech Pathology and Audiology, Research Institute of Audiology and Speech Pathology, Hallym University, Chuncheon, Korea
}

Correspondence: Hyunsook Jang, PhD Department of Speech Pathology and Audiology, Hallym University, 1 Hallimdaehak-gil, Chuncheon 24252, Korea

Tel: $+82-33-248-2218$

Fax: +82-33-256-3420

E-mail: hsjang@hallym.ac.kr

Received: October 20, 2019

Revised: November 14, 2019

Accepted: November 25, 2019

This research was supported by Hallym University Research Fund (No. HRF-201708-007).

\begin{abstract}
Objectives: This study aimed to investigate the list equivalency of the Korean StandardSentence List for Adults (KS-SL-A) in visual-only (VO) presentation conditions and to measure sentence recognition abilities for normal and hearing impaired individuals in $\mathrm{VO}$ and auditory-visual (AV) conditions. Methods: Sentences from the KS-SL-A, spoken by both males and females, were filmed and subsequently presented to 32 normal-hearing subjects in $\mathrm{VO}$ conditions, and to 21 normal subjects and 11 hearing-impaired subjects in VO and $\mathrm{AV}(+5,+10,+15 \mathrm{~dB} S \mathrm{~L})$ conditions. Subjects were asked to identify sentences in VO and $\mathrm{AV}$ conditions. KS sentence lists of 10 everyday sentences were determined based on keyword accuracy. Auditory and visual enhancements were also calculated. Results: ANOVA revealed significant differences in sentence lists, and post hoc tests indicated that the following four lists were determined to be equivalent: List 1, 3, 4, and 6. Subjects with hearing impairment showed significantly higher scores in VO and $+5 \mathrm{~dB} A V$ conditions, while subjects with normal hearing had significantly better performance in $+15 \mathrm{~dB} A V$ condition. Conclusion: These findings suggest that individuals with hearing impaired are more reliant on visual speech information than individuals with normal hearing, but have been shown to develop their speech-reading ability along with auditory information. Therefore, speech recognition should be obtained in AV conditions as well as in AO conditions for clinical use in order to provide the best recommendation and rehabilitation.
\end{abstract}

Keywords: Korean Standard-Sentence List for Adults (KS-SL-A), Sentence recognition, Visual-only condition, Auditory-visual condition, List equivalency, Hearing impaired
독화는 입, 얼굴 및 신체 움직임의 시각적 정보와 음향적 신호의 청각적 정보를 모두 이용하여 어음을 인지하는 방법(Choi, Yoon, Ryu, \& Jang, 2017; Oliveira, Soares, \& Chiari, 2014; Strelnikov et al., 2015)으로 청각장애인 대다수의 주된 의사소통 방식으로 널리 사용되고 있으며, 청력손실의 정도가 심할수록 그 의존의 정도도 커진다(Arnold \& Hill, 2001; Dodd, 1977; Grant \& Seitz, 1998; Grant, Walden, \& Seitz, 1998; Woll, 2012). 최근 인공와우와 보청기 기술 의 비약적인 발전으로 고심도 청각장애인도 청각 기능의 회복이 상 당부분 보장되지만(Gaylor et al., 2013; Park et al., 2016), 보장구에 대한 적응이 이루어진 후에도 어음인지에서 독화에 크게 의존한다
(Oxenham \& Kreft, 2014). 그러므로 의사소통의 전제가 되는 어음 인지는 청각 정보와 시각 정보 중 어느 하나에만 의존하지 않고 양 자를 통합하여 이루어지는 과정(McGurk \& MacDonald, 1976)으 로, 청자의 시각 정보와 청각 정보에서 단서를 이끌어내는 능력, 시 각 정보와 청각 정보를 통합하는 능력, 청각 및 시각 정보들을 통합 하여 말을 인지하는 과정에 관여하는 언어지식 등에 영향을 받을 수 있다(Grant \& Seitz, 1998, 2000; Grant et al., 1998). 독화 수행력 은 인공와우를 통한 이익을 예측할 수 있는 지표가 될 수 있는데 (Bergeson \& Pisoni, 2004), Geers와 Brenner (1994)는 인공와우 수 술 후 3 년이 경과한 시점에서 피검자들의 $\mathrm{AV}$ 조건에서의 독화 수행 
Jonghyun Kwak, et al. • Stentence Recognition in Visual-Only and Audiotry-Visual Conditions

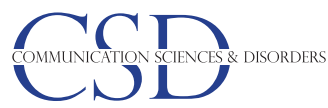

도가 VO 조건에 비해 높아지기 시작했음을 보고하였으며, Geers, Brenner와 Davidson (2003)은 5세 이전에 인공와우 수술을 받은 아동의 평균 말인지가 $\mathrm{VO}$ 조건에서 $40 \%, \mathrm{AO}$ 조건에서 $50 \%, \mathrm{AV}$ 조건에서 $80 \%$ 로 나타났음을 보고하였다.

임상에서 청각장애인의 일상생활 의사소통능력평가 및 재활계 획에 대한 정보 제공 등을 목적으로 실시하는 어음인지도 검사는 듣기에 가장 적절한 강도로 단어 또는 문장 등의 어음을 제시하여 피검자가 정확히 확인하는 정도를 측정하는 검사(American SpeechLanguage-Hearing Association, 1988)로, 주로 방음실에서 청각 정 보만 제공되는 상황(auditory-only, AO)에서 시행된다. 그러나 청각 정보만을 통한 평가의 결과가 방음실을 벗어난 일상생활에서의 의 사소통능력을 측정하기에는 제한적일 수 있는데, 청력손실의 유무 와는 별개로 모든 사람이 의사소통을 위해 청각 및 시각적 단서를 활용하는 독화를 사용하기 때문이다. 그러므로 임상에서 청각장 애인의 실질적 의사소통 능력을 예측하고 중재를 도모하기 위해 $\mathrm{AO}$ 조건뿐 아니라 청각과 시각 정보가 제공되는(auditory-visual, $\mathrm{AV}$ ) 조건에서 어음인지도 검사를 실시할 필요가 있다. 특히 $\mathrm{AV}$ 조 건에서의 어음인지도는 시각 단서만 제시하는 조건(visual-only, $\mathrm{VO}$ )을 통해 청각 이득(auditory enhancement)을 측정하고, 이를 $\mathrm{AO}$ 조건과 비교함으로써 시각 이득(visual enhancement)을 측정 할 수 있으며, 이를 바탕으로 청각장애인의 의사소통 특성 및 보장 구 착용이득에 관한 정보를 파악할수 있다는 장점이 있다(Tye-Murray, 2014).

이러한 이유로 영어권에서는 기존의 어음인지도 검사를 독화수 행력 평가에도 적용하고자 하였다(Calhoun, Janson, \& Valencia, 1988; Wilson, Dancer, \& Stamper, 1984). 특히 임상에서 일상생활 문장인지도를 측정하기 위하여 널리 사용하고 있는 CID Everyday Sentences의 경우 AO 검사로 개발되었지만(Davis \& Silverman, 1970), 추후 연구들을 통해 독화검사로의 활용 가능성을 제시하였 다(Dancer, Krain, Thompson, \& Davis, 1994; Wilson et al., 1984). Calhoun 등(1988)은 건청 성인들을 대상으로 독순(lip reading) 검 사인 Utley Lipreading Forms와 CID Everyday Sentence 검사 목록 간 독순 수행력의 동등성 여부를 확인하였다. 또한, Wilson 등(1984) 은 건청 성인을 대상으로 CID Everyday Sentence Lists의 시각적 난이도를 측정하여 목록 간 차이를 보고하면서 독화 훈련 및 훈련 전후 효과의 검증에 사용되는 목록의 선택에 유의해야 함을 지적 하고 시각적 난이도가 동등한 목록을 사용할 것을 제안하였다. Dancer 등(1994)은 CID Everyday Sentence 검사의 목록 A와 B를 독화검사에 이용하였고, Wilson 등(1984)은 $\mathrm{VO}$ 조건에서 CID 문 장목록 간 서로 유의미하게 높은 상관관계를 보인다고 보고하였다.
또한 CID 일상생활 문장검사가 다른 독화검사와도 좋은 상관성이 있으며 언어습득 전 농인 성인과 청소년에게도 적용하고 표준화 작 업을 통해 $\mathrm{AO}$ 조건뿐 아니라 $\mathrm{VO}$ 및 $\mathrm{AV}$ 조건에서도 사용 가능함 을 증명하였다(Davis \& Silverman, 1970).

현재 국내 임상에서 어음인지도 검사도구로 사용되고 있는 한국 표준 문장표(Korean Standard Sentence List, KS-SL)는 CID Everyday Sentence 검사의 개발 기준에 의거하여 개발된 한국어 일상 생활 문장검사이다(Jang et al., 2008b). 이 문장표는 각 목록당 10개 의 일상생활 문장으로 구성된 총 8 개의 목록으로, 표준화 과정에 서 목록 간 어휘 선정, 문장 길이, 문법 구조 등의 균등한 배치와 주 파수 특성 및 심리음향기능곡선 분석을 통해 $\mathrm{AO}$ 조건에서의 목록 간 난이도의 동등성이 검증된 도구이다. 그러나 $\mathrm{VO}$ 조건에서 목록 간 시각적 난이도에 대한 동등성 여부는 검증되어 있지 않아 $\mathrm{AV}$ 조 건에서의 어음인지도 측정에서 청각 및 시각 단서의 영향력을 평가 하기가 어렵다. 예를 들어 어떤 특정 목록이 시각적으로 쉬운 난이 도를 가진 경우, $\mathrm{AV}$ 상황에서의 인지도 점수가 상대적으로 높게 나 타날 수 있으므로 청각 이득에 대한 신뢰성이나 타당성에 대한 문 제가 제기될 수 있다. 그러므로 일상생활 속에서 청각과 시각을 모 두 활용하는 청각장애인의 실질적 의사소통능력을 측정하는 도구 로 KS-SL를 활용하기 위해 우선 $\mathrm{VO}$ 조건에서 문장표의 목록 간 난 이도를 측정할 필요가 있다. 이에 본 연구는 KS-SL의 목록 간 시각 적 난이도에 대한 동등성을 검증하고, 이를 바탕으로 $\mathrm{VO}$ 및 $\mathrm{AV}$ 조 건에서 건청인과 청각장애인의 문장인지도를 비교함으로써 청각 장애인의 시각 및 청각 정보의 활용 정도를 확인하고, 나아가 청각 장애인의 문장인지도 평가가 $\mathrm{AO}$ 조건만 아니라 $\mathrm{AV}$ 및 $\mathrm{VO}$ 조건에 서도 이루어져야 할 필요성을 확인하는 데 그 목적이 있다.

\section{연구방법}

\section{연구대상}

본 연구를 위하여 두 가지 실험을 진행하였다. 실험 I은 VO 조건 에서 검사목록 간 난이도의 동등성을 측정하였는데 정상 청력과 교정시력 0.8 이상인 20대(평균연령 21;5세) 성인 32명(남 19명, 여 13 명)을 대상으로 하였다. 실험II은 실험I의 난이도가 동등한 목록 을 사용하여 $\mathrm{VO}$ 및 $\mathrm{AV}$ 제시 조건에 따른 문장인지도를 확인하였 으며, 만 20세 이상 40 세 미만(평균연령 27;6세)의 교정시력이 0.8 이상인 건청인 21 명(남 11 , 여 10)과 청각장애인 11명(남 6, 여 5)을 대상으로 하였다. 실험I의 대상자들이 정상청력임을 확인하기 위 해 방음실에서 청력검사기(GSI 61; Grason-Stadler, Eden Prairie, $\mathrm{MN}, \mathrm{USA}$ )를 사용하여 헤드폰(TDH-39; Telephonics Corporation, 
Table 1. Characteristics of subjects with hearing loss

\begin{tabular}{|c|c|c|c|c|c|c|c|c|}
\hline \multirow{2}{*}{$\begin{array}{c}\text { Subject } \\
\text { No. }\end{array}$} & \multirow{2}{*}{ Sex } & \multirow{2}{*}{$\begin{array}{c}\text { CA } \\
(y r ; m o)\end{array}$} & \multirow{2}{*}{$\begin{array}{c}\text { HL on- } \\
\text { set age } \\
\text { (yr) }\end{array}$} & \multicolumn{2}{|c|}{ Hearing device } & \multicolumn{2}{|c|}{ Wearing period (yr) } & \multirow{2}{*}{$\begin{array}{l}\text { Aided } \\
\text { threshold } \\
(\mathrm{dB} \mathrm{HL})\end{array}$} \\
\hline & & & & Right & Left & HA & $\mathrm{Cl}$ & \\
\hline 1 & $\mathrm{~F}$ & $20 ; 3$ & 5 & $\mathrm{HA}$ & $\mathrm{Cl}$ & 16 & 0.9 & 38.75 \\
\hline 2 & $\mathrm{~F}$ & $20 ; 10$ & 1 & $\mathrm{Cl}$ & - & - & 14.3 & 24.50 \\
\hline 3 & M & $21 ; 3$ & 3 & HA & $\mathrm{Cl}$ & 18 & 7.9 & 29.75 \\
\hline 4 & M & $21 ; 3$ & 3 & $\mathrm{Cl}$ & - & - & 18.5 & 27.50 \\
\hline 5 & $F$ & $29 ; 4$ & 1 & $\mathrm{HA}$ & $\mathrm{Cl}$ & 26 & 15.0 & 50.00 \\
\hline 6 & $F$ & $33 ; 0$ & 5 & - & $\mathrm{Cl}$ & - & 14.2 & 26.25 \\
\hline 7 & M & $22 ; 7$ & 1 & $\mathrm{HA}$ & $\mathrm{HA}$ & & 18 & 50.62 \\
\hline 8 & $F$ & $28 ; 11$ & 1 & HA & - & & 26 & 84.37 \\
\hline 9 & M & $34 ; 5$ & 3 & HA & - & & 30 & 45.00 \\
\hline 10 & M & $36 ; 0$ & 3 & HA & $\mathrm{HA}$ & & 17 & 78.15 \\
\hline 11 & M & $36 ; 11$ & 1 & HA & $\mathrm{HA}$ & & 30 & 82.50 \\
\hline
\end{tabular}

$\mathrm{CA}=$ chronological age; $\mathrm{HL}=$ hearing loss; $\mathrm{R}=$ right; $\mathrm{L}=$ left; $\mathrm{HA}=$ hearing aid; $\mathrm{Cl}=$ cochlear implant; Aided threshold=average threshold at 500, 1,000, 2,000, and $4,000 \mathrm{~Hz}$.

Farmingdale, NY, USA)을 착용한 후 순음청력검사를 진행하였으 며, 대상자들은 $250-8,000 \mathrm{~Hz}$ 의 청력 역치가 양쪽 귀 모두 $20 \mathrm{~dB}$ $\mathrm{HL}$ 이하로 정상 범위에 속하였다. 건청인 대상자의 $500,1,000,2,000$, $4,000 \mathrm{~Hz}$ 4개 주파수에서의 순음역치평균(pure-tone threshold average, PTA)은 우측 귀 $3.53 \pm 3.72 \mathrm{~dB} \mathrm{HL}$, 좌측 귀 $4.31 \pm 3.73$ $\mathrm{dB} \mathrm{HL}$ 이었다. 청각장애인은 모두 고심도 난청으로서 보청기 사용 자는 5명, 인공와우(cochlear implant, $\mathrm{CI}$ ) 사용자는 6명이었다. 보 청기 사용자의 경우 착용 역치와 미착용 역치를, CI 착용자의 경우 착용 역치만 구하였다. 착용 역치를 구할 때는 대상자를 스피커 (JBL CONTROL 1Xtreme) 정면( $\left.0^{\circ}\right) 1 \mathrm{~m}$ 거리에 위치시키고, 와블 톤을 사용하여 $500,1,000,2,000,4,000 \mathrm{~Hz}$ 역치를 구하였다. 보장 구의 평균 착용기간은 보청기 24.2년, CI 11.8년이었으며, 보청기 사 용자의 경우에는 만 19세부터 보청기를 착용해 온 1명(S10)의 연구 대상자를 제외하면 나머지 4명 모두 5세 전후로 보청기를 착용해 왔다고 보고하였다. 청각장애인 개별 정보는 Table 1에 제시하였다. 본 연구의 모든 대상자들은 연구목적과 내용에 대한 설명을 듣고, 자발적으로 연구에 참여하기로 결정하였으며 연구참여동의서를 작성한 후 연구에 참여하였다.

\section{검사도구}

본 연구의 문장인지도 검사를 위하여 총 8 개 목록으로 각 목록 당 10 개 문장, 40 개 목표단어로 구성된 한국표준 어음청각검사의 문장표 일반용(Jang et al., 2008b)을 사용하였으며, 검사의 친숙도 를 위한 연습목록으로 한국표준 어음청각검사의 학령기용 문장표 (Jang, Lee, Lim, Jeon, \& Hyun, 2008a)의 목록1을 사용하였다. 문
장표의 동영상 제작은 소음이 없는 방음실에서 정면 $\left(0^{\circ}\right) 1.5 \mathrm{~m}$ 거리 에서 표준어를 사용하는 20 대 남성 화자와 여성 화자에게 일상생 활에서처럼 자연스럽게 문장을 말하도록 하였으며, 이때 얼굴 근육 의 움직임과 어깨의 움직임을 확인할 수 있도록 얼굴과 흥부 상부 까지 화면에 나오도록 삼성 갤럭시 노트 5 (SM-N920S; Samsung, Korea)를 사용하여 UHD $4 \mathrm{~K}(3,840 \times 2,160), 30 \mathrm{fps}$ 로 촬영하였다. 촬영된 영상은 동영상 편집 프로그램(Sum Editor 7.2; SerialReactor, USA)과 음원 편집 프로그램(Adobe Audition CC; Adobe Systems, USA)을 사용하여 편집하였다. 문항과 문항 사이의 간격은 연 구 대상자가 충분히 답할 수 있도록 음절당 1 초로 계산하고 추가 5 초를 더한 간격으로 구성하였으며, 각 문항이 시작되기 전 화면에 5 초의 카운트다운 숫자를 제시하여 연구대상자가 문항 시작에 준비 하도록 하였다. 이때, 제작된 동영상 문항의 선정 기준은 연구자를 포함한 언어병리학 및 청각학전공 석사와 박사 5명이 (1) AO 상황 에서 $100 \%$ 인지도를 나타낸 문항, (2) AV 상황에서 청각 자극에 따 른 화자의 입모양이 자연스럽다고 $100 \%$ 판정한 문항으로 하였다. 녹음된 음성은 Adobe Audition CC를 사용하여 말소리의 진폭을 일정하게 조절하는 노멀라이징 과정을 거친 후, 소음측정기(Modular precision sound analyzer type 2260; Bruel \& Kjaer, Denmark) 에서 평균 $70 \mathrm{~dB} \mathrm{SPL}$ 로 측정되도록 조절하였다. 제작된 문장인지 도 검사 목록은 모니터(Dell Monitor, 2,412 m, 1,920×2,988; Dell, USA)를 사용하여 제시하였다.

\section{연구절차}

실험I에서는 VO 조건에서 $\mathrm{KS}-\mathrm{SL}$ 의 목록 간 동등성을 검사하기 위하여 건청 성인 32명을 대상으로 시각적 문장인지도를 측정하였 다. 이를 위하여 소음이 통제된 방에서 연구대상자의 정면에 컴퓨 터 모니터를 위치시키고 영상을 제시하여, 화면을 통해 제시되는 문장을 발화하는 화자의 얼굴 및 입모양을 보면서 인지한 대로 따 라 말하도록 하였다. 연습 목록으로 KS-SL 학령기용(Jang et al., 2008a) 목록1 중 1-5번을 본 실험방법과 동일하게 제시하여 검사수 행방법을 잘 이해하고 있는지 확인한 후, 본 검사를 실시하였다. 목 록제시 순서는 무작위로 하였으며, 소요시간은 약 60 분이었다.

실험II는 실험I에서 난이도가 동등한 목록을 사용하여 VO 및 $\mathrm{AV}$ 제시 조건에 따른 문장인지도를 확인하고자 실험I에 참여하지 않은 다른 건청인과 청각장애인을 대상으로 검사를 실시하였다. 실 험I과 다른 건청인을 대상으로 검사를 진행한 이유는 동일 목록 사 용에 따른 학습효과를 배제하기 위함이었다. 실험II의 VO 조건은 실험과 동일한 조건에서 진행하였다. $\mathrm{AV}$ 조건의 경우는 방음실에 서 노트북 컴퓨터와 연결된 모니터(Dell 2,412M, $1,920 \times 1,200)$ 로 
사전에 녹화된 영상자료를 상영하였고, 청각 정보는 청력검사기의 외부 단자에 연결된 노트북 컴퓨터를 통해 제시하였으며, 모든 검 사는 보정 톤이 재생될 때 청력검사기 내 VU 미터가 0 위치를 가리 키도록 노트북 컴퓨터와 청력검사기의 소리 크기를 조절하는 과정 을 거쳤다.

건청인 대상자는 청력역치가 더 좋은 쪽의 귀를 기준으로 헤드 폰(TDH-50)을 통해 진행하였으며, 양쪽의 역치가 동일한 경우에 는 우측 귀로 실시하였다. 모니터 화면에서 제시되는 얼굴 및 입모 양을 보면서 인지한 대로 따라 말하도록 안내하였다. 청각장애인은 보장구를 착용한 상태에서 스피커로 자극을 제시하였으며, 양이보 청기 사용자는 착용역치가 더 좋은 쪽의 보청기만, 인공와우와 보 청기를 함께 착용한 경우 인공와우만 착용한 상태에서 진행하였다. 청각장애인의 경우에는 답안지에 옮겨 적도록 안내하였다. 청각 정 보를 제시할 때의 강도 수준은 건청인의 경우 PTA를 기준으로 수 행도가 $90 \%$ 이상에 도달하는 수준까지 $5 \mathrm{~dB}$ 씩 증가시키면서 제시 하였으며, 청각장애인의 경우 보장구 착용역치 평균을 기준으로 쾌 적역치(most comfortable level, MCL)에 도달하는 수준까지 $5 \mathrm{~dB}$ 씩 증가시키면서 제시하였다. 청각장애인의 경우 $\mathrm{MCL}$ 에서 $\mathrm{AO}$ 조 건으로 동등성 검사에 사용되지 않은 문장표의 목록을 사용하여 검사를 실시하였다. 실험 과정에서 피로효과를 방지하고자 연구대 상자가 요구하면 언제든지 휴식을 취하도록 하였다. 문장인지도의 점수 산정은 목록당 10 개의 문장 정반응수와 목표단어 40 개에 대 한 정반응수를 기준으로 백분율을 구하였다. 또한 Sommers, TyeMurray와 Spehar (2005)의 청각 이득은 (AV-VO)/(100-VO)과 시 각 이득 $(\mathrm{AV}-\mathrm{AO}) /(100-\mathrm{AO})$ 공식을 사용하여 청각장애 대상자들 의 청각이득과 시각이득을 산정하였다.

\section{통계분석}

통계 분석은 SPSS Statistics version 23.0 (IBM Corp., Armonk, $\mathrm{NY}, \mathrm{USA})$ 을 이용하여 전체 대상자의 문장인지도 점수의 평균과 표준편차 등 기술통계를 실시하였다. $\mathrm{VO}$ 조건에서 8 개 목록 간 문 장과 목표단어 정반응의 동등성을 분석하기 위하여 각각 반복측 정 일원분산분석과 사후검정으로 대비검정을 실시하였으며. 각 목 록별 문장과 목표단어 정반응률 간 차이 비교는 대응표본 $t$-test를 실시하였다. $\mathrm{AV}$ 조건에서 건청인 집단과 청각장애인 집단 각각의 제시 강도와 목록에 따른 수행도 차이를 확인하기 위해 반복측정 이원분산분석을 실시하였다. 상호작용 효과가 나타난 경우에 제시 조건과 목록에 따른 수행도에 대한 일원분산분석을 실시하였으며, 유의미한 차이가 나타날 경우 Bonferroni 사후분석을 실시하였다. 청각정보 제시 조건별로 청각장애인과 건청인 간 수행력에 차이가
있는지 알아보기 위하여 독립표본 $t$-test를 유의수준 .05 에서 검증 하였다. 분산분석 시 Mauchly 구형성 가정이 충족되지 않은 경우 는 Greenhouse-Gasser 검증을 하였으며, 다중비교로 인한 1종 오 류의 증가를 조정하기 위해서 Bonferroni alpha correction을 사용 하여 유의도를 검증하였다.

\section{연구결과}

\section{$\mathrm{VO}$ 조건에서 한국표준 문장표의 목록 간 동등성}

$\mathrm{VO}$ 조건에서 건청 성인의 문장 및 목표단어 정반응률의 평균과 표준편차는 Table 2 와 같다. 전체 문장 정반응률의 평균과 표준편 차는 $10.55 \% \pm 12.97 \%$, 평균 점수 범위는 5.63\%-17.50\%였다. 목록 간 문장 정반응률에서 유의한 차이 $\left(F_{(7,217)}=7.864, p<.001\right)$ 를 보였 으며, 목록 $1,6,8$ 과 5,7 , 목록 2 와 3 , 목록 3 과 $2,5,7$, 목록 5 와 1,3 , 6,8 , 목록 7과 1,3 에서 유의한 차이를 나타내었다. 전체 목표단어 정반응률의 평균과 표준편차는 $22.22 \% \pm 15.75 \%$ 였으며, 목록 8 이 $14.69 \% \pm 16.27 \%$ 의 가장 낮은 점수를, 목록 7이 $32.11 \% \pm 16.83 \%$ 의 가장 높은 점수를 보였다. 목표단어 정반응률에서 목록 간 유의 한 차이 $\left(F_{(7,217)}=22.873, p<.001\right)$ 를 보였으며, 목록 $1,3,4,6$ 은 5,7 , 목록 2 와 $3,7,8$, 목록 5 와 $1,3,4,6,8$, 목록 7과 $1,2,3,4,6,8$, 목록 8 과 $2,5,7$ 에서 유의한 차이를 보였으나 목록 $1,3,4,6$ 에서는 유의미 한 차이가 없었다. 목록별 문장 정반응률과 목표단어 정반응률 간 을 비교하기 위하여 대응표본 $t$-test를 실시한 결과, 모든 목록에서 목표단어 정반응률이 유의하게 높게 나타났다 $(p<.05)$.

Table 2. Descriptive statistics and statistical results of correct responses of the sentences and target words in visual-only condition

\begin{tabular}{lcrc}
\hline & Sentence (\%) & Target words (\%) & \multicolumn{1}{c}{$t$-test } \\
\hline List 1 & $6.56^{\mathrm{a}, \mathrm{b}}(9.71)$ & $20.63^{\mathrm{a}, \mathrm{b}, \mathrm{c}}(15.58)$ & $-7.943^{* * *}$ \\
List 2 & $11.88^{\mathrm{b}, \mathrm{c}}(12.56)$ & $24.45^{\mathrm{b}, \mathrm{c}}(16.48)$ & $-9.924^{* * *}$ \\
List 3 & $5.63^{\mathrm{a}}(8.40)$ & $16.64^{\mathrm{a}, \mathrm{b}}(12.17)$ & $-6.976^{* * *}$ \\
List 4 & $11.88^{\mathrm{b}, \mathrm{c}}(14.01)$ & $20.00^{\mathrm{a}, \mathrm{b}, \mathrm{c}}(16.45)$ & $-5.758^{* * *}$ \\
List 5 & $17.50^{\mathrm{c}}(14.81)$ & $30.63^{\mathrm{c}}(14.85)$ & $-8.739^{* * *}$ \\
List 6 & $10.00^{\mathrm{a}, \mathrm{b}}(15.03)$ & $18.67^{\mathrm{a}, \mathrm{b}}(17.32)$ & $-5.960^{* * *}$ \\
List 7 & $13.70^{\mathrm{c}}(14.08)$ & $32.11^{\mathrm{c}}(16.83)$ & $-9.163^{* * *}$ \\
List 8 & $7.19^{\mathrm{a}, \mathrm{b}}(10.23)$ & $14.69^{\mathrm{a}}(16.27)$ & $-4.809^{* * *}$ \\
Overall & $10.55(12.97)$ & $22.22(15.75)$ & $-19.740^{* * *}$ \\
F-value & $7.864^{* * *}$ & $22.873^{* * *}$ & \\
\hline
\end{tabular}

Values are presented as mean (SD).

${ }^{* * *} p<.001$, different letters $(\mathrm{a}, \mathrm{b}, \mathrm{c})$ mean significantly different $(p<.05)$ in posthoc tests. 


\section{건청인과 청각장애인의 $\mathrm{VO}$ 및 $\mathrm{AV}$ 제시조건에 따른 수행력} 건청인의 $\mathrm{VO}$ 및 $\mathrm{AV}$ 제시 조건에 따른 문장인지도

실험의 $\mathrm{VO}$ 조건에서 난이도의 동등성이 확인된 목록 $(1,3,4,6)$ 을 사용하여 실험I에 참여하지 않은 건청인 21 명을 대상으로 $\mathrm{VO}$ 조건과 $\mathrm{AV}$ 조건에서 문장인지도를 측정한 결과는 Table 3 과 같다. $\mathrm{VO}$ 조건에서 전체 평균 문장인지도는 $14.24 \%$ 였으며, $\mathrm{AV}$ 조건에서 제시 강도 수준을 $5 \mathrm{~dB}$ 간격으로 $15 \mathrm{~dB} \mathrm{SL}$ 까지 증가시켰을 때, 전체 목록의 평균 문장인지도는 42.80\%-93.07\%로 증가하였다.

반복측정 이원분산분석을 실시하여 건청인 집단에서 제시 강도 $(0,5,10,15 \mathrm{~dB} \mathrm{SL})$ 와 문장 목록 $(1,3,4,6)$ 에 따른 문장인지도를 살 펴본 결과, 제시 강도와 목록 간 $\left(F_{(4.594,79.183)}=0.758, p>.05\right)$ 상호작용 은 유의미하지 않았으나, 제시 강도 $\left(F_{(3,101,120.330)}=202.492, p<.05\right)$ 와 목록 $\left(F_{(3,282.949)}=3.106, p<.05\right)$ 의 주효과는 유의미한 것으로 나 타났다. 사후분석 결과, 제시 강도가 $5 \mathrm{~dB}$ 씩 증가함에 따라 수행도 가 유의하게 증가하였으며, 목록 1의 수행도가 목록 3 에 비해 유의 하게 높은 것으로 나타났다.

목록별 제시 강도에 따른 반복측정 일원분산분석 결과(Table 3), 모든 목록에서 제시 강도가 $5 \mathrm{~dB}$ 씩 증가할 때마다 문장인지도 수 행력이 유의미하게 증가하였다 $(p<.05)$. 그러나 제시 강도별 목록 에 따른 반복측정 일원분산분석 결과(Table 3 ), 모든 강도 수준에 서 목록간 유의미한차이는 없었다( $p>.05)$.

\section{청각장애인의 $\mathrm{VO}$ 및 $\mathrm{AV}$ 제시 조건에 따른 문장인지도}

실험 I의 $\mathrm{VO}$ 조건에서 난이도의 동등성이 확인된 목록 $(1,3,4,6)$ 을 사용하여 청각장애인 11 명을 대상으로 $\mathrm{VO}$ 조건과 $\mathrm{AV}$ 조건에 서 문장인지도를 측정한 결과는 Table 4와 같다. $\mathrm{VO}$ 조건에서 전체 목록의 평균 문장인지도는 $32.24 \%$ 였으며, $\mathrm{AV}$ 조건에서 제시 강도 수준을 $5 \mathrm{~dB}$ 간격으로 $15 \mathrm{~dB}$ SL까지 증가시켰을 때, 문장인지도는

Table 3. Statistical results of percent correct among lists in VO and AV conditions for subjects with normal hearing

\begin{tabular}{lccccc}
\hline & \multicolumn{4}{c}{ Presentation conditions (\%) } & \multirow{2}{*}{ F-value } \\
\cline { 2 - 5 } & VO & $5 \mathrm{dBSL}$ & $10 \mathrm{~dB} \mathrm{SL}$ & $15 \mathrm{~dB} \mathrm{SL}$ & \\
\hline List 1 & $15.36(13.90)$ & $45.83(22.41)$ & $76.19(17.42)$ & $95.24(3.78)$ & $210.843^{* * *}$ \\
List 3 & $11.14(12.86)$ & $38.93(24.16)$ & $72.74(22.82)$ & $92.02(11.42)$ & $121.479^{* * *}$ \\
List 4 & $16.31(16.14)$ & $42.26(24.85)$ & $72.98(18.97)$ & $91.43(10.11)$ & $102.642^{* * *}$ \\
List 6 & $14.17(13.79)$ & $44.17(24.37)$ & $73.62(26.25)$ & $93.57(10.86)$ & $144.405^{* * *}$ \\
Overall & $14.24(14.10)$ & $42.80(23.67)$ & $73.88(21.29)$ & $93.07(9.49)$ & $567.294^{* * *}$ \\
F-value & 3.033 & 0.960 & 2.275 & 1.136 & \\
\hline
\end{tabular}

Values are presented as mean (SD).

$\mathrm{VO}=$ visual-only; $\mathrm{AV}=$ auditory-visual.

${ }^{* * *} p<.001$, sentences were presented at 5,10 , and $15 \mathrm{~dB} \mathrm{SL}$ in auditory-visual condition.
63.98\%-82.56\%로 증가하였다.

청각장애인 집단에서 제시 강도와 문장 목록에 따른 인지도의 차이를 살펴보기 위해 반복측정 이원분산분석을 실시한 결과, 제시 강도와 목록 간 상호작용은 유의하지 않았으나 $\left(F_{(4.113,130.001)}=1.045\right.$, $p>.05)$, 제시 강도 $\left(F_{(1.800,38106.992)}=74.201, p<.05\right)$ 와 목록 $\left(F_{(3,936.047)}=\right.$ $7.015, p<.05)$ 의 주효과는 유의미한 것으로 나타났다. 제시 강도에 대한 사후분석 결과, 제시 강도가 $5 \mathrm{~dB}$ 단위로 증가할 때마다 수행 도가 유의미하게 높았으며, 목록에 대한 사후분석 결과, $\mathrm{VO}$ 조건 을 제외하면 목록 1 이 목록 3 , 목록 4 에 비해 유의하게 높았다. 목록 별 제시 강도에 따른 일원분산분석 결과(Table 4), 모든 목록에서 유의미한 차이를 보였다 $(p<.05)$. 제시 강도별 목록에 따른 일원분 산분석 결과(Table 4), $\mathrm{VO}$ 조건에서는 유의미한 차이가 없었으나

Table 4. Statistical results of percent correct of overall and among the lists in $\mathrm{VO}$ and $\mathrm{AV}$ conditions in hearing impaired group

\begin{tabular}{lccccc}
\hline \multicolumn{5}{c}{ Presentation conditions (\%) } & \multirow{2}{*}{ F-value } \\
\cline { 2 - 5 } & VO & $5 \mathrm{dBSL}$ & $10 \mathrm{dBSL}$ & $15 \mathrm{dBSL}$ & \\
\hline List1 & $35.82(17.91)$ & $72.73(17.16)$ & $84.32(12.80)$ & $87.27(14.42)$ & $52.243^{* * *}$ \\
List3 & $30.45(19.55)$ & $59.32(19.94)$ & $72.95(18.53)$ & $77.05(19.62)$ & $29.940^{* * *}$ \\
List 4 & $27.91(11.38)$ & $57.95(17.60)$ & $77.95(16.84)$ & $81.14(16.52)$ & $65.584^{* * *}$ \\
List 6 & $34.77(12.42)$ & $65.91(19.28)$ & $78.18(19.04)$ & $84.77(17.41)$ & $55.640^{* * *}$ \\
Overall & $32.24(15.49)$ & $63.98(18.83)$ & $78.35(16.88)$ & $82.56(16.94)$ & $18.652^{* * *}$ \\
F-value & 1.279 & $5.335^{*}$ & $4.231^{*}$ & $6.296^{* *}$ & \\
\hline
\end{tabular}

Values are presented as mean (SD).

$\mathrm{VO}=$ visual-only; $\mathrm{AV}=$ auditory-visual.

${ }^{*} p<.05,{ }^{* *} p<.01,{ }^{* * *} p<.001$, sentences were presented at 5,10 , and $15 \mathrm{~dB} S \mathrm{~L}$ in $\mathrm{AV}$ condition.

Table 5. Auditory and visual enhancement in individuals with hearing impairment

\begin{tabular}{cccccccc}
\hline \multirow{2}{*}{ Group } & $\begin{array}{c}\text { Subject } \\
\text { No. }\end{array}$ & \multicolumn{3}{c}{ Presentation conditions (\%) } & & \multicolumn{2}{c}{ Enhancement (\%) } \\
\cline { 8 - 9 } \cline { 7 - 8 } Cl & 1 & 84.38 & 12.50 & 60.00 & & 82.15 & 61.00 \\
& 2 & 83.75 & 40.00 & 15.00 & & 79.92 & 80.90 \\
& 3 & 96.00 & 32.50 & 90.00 & & 94.07 & 60.00 \\
& 4 & 87.50 & 27.50 & 82.50 & & 82.76 & 28.60 \\
& 5 & 95.63 & 43.00 & 20.00 & & 92.33 & 94.50 \\
& 6 & 44.38 & 23.13 & 0 & & 27.64 & 44.40 \\
HA & 7 & 100 & 41.25 & 0 & & 100 & 100 \\
& 8 & 78.75 & 40.38 & 0 & & 64.36 & 78.80 \\
& 9 & 95.00 & 23.13 & 0 & & 93.50 & 95.00 \\
& 10 & 93.00 & 17.50 & 90.00 & & 91.52 & 30.00 \\
& 11 & 88.75 & 53.75 & 0 & & 75.68 & 88.75 \\
\hline
\end{tabular}

$\mathrm{Cl}=$ cochlear implant; $\mathrm{HA}=$ hearing aid; $\mathrm{AV}=$ auditory-visual condition; $\mathrm{VO}=$ visualonly condition; $\mathrm{AO}=$ auditory-only condition.

Enhancement calculated with: auditory $=\frac{A V-V O}{100-V O}$, visual $=\frac{A V-A O}{100-A O}$ 


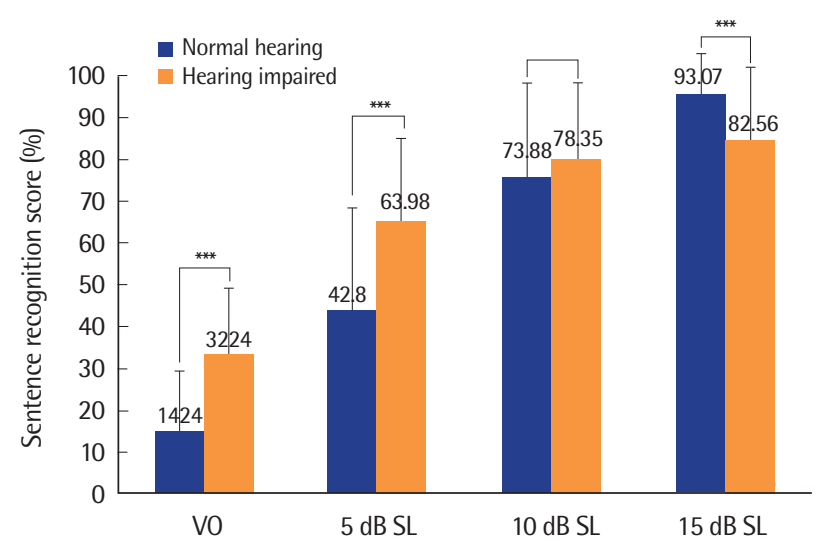

Figure 1. Comparison of performance between normal and hearing-impaired groups in $\mathrm{VO}$ and $\mathrm{AV}$ conditions.

$\mathrm{VO}=$ visual-only; $\mathrm{AV}=$ auditory-visual. ${ }^{* * *} p<.001$.

( $p>$.05), $\mathrm{AV} 5,10,15 \mathrm{~dB}$ SL 조건에서는 유의미한 차이가 있었다 $(p<.05)$.

본 연구에 참여한 청각장애인 11 명 개인별 $\mathrm{AV}, \mathrm{VO}, \mathrm{AO}$ 조건에서 의 수행력과 청각 이득과 시각 이득을 살펴본 결과(Table 5), 청각 이득의 범위는 $27.64 \%-100 \%$, 시각 이득은 $28.6 \%-100 \%$ 로 큰 개인 차를 보였다. 청각 이득이 시각 이득보다 큰 것으로 나타난 대상자 는 S10을 제외하고 $\mathrm{S} 1, \mathrm{~S} 3, \mathrm{~S} 4$ 로 인공와우 사용자였으며, 시각 이득 이 청각 이득보다 큰 것으로 나타난 대상자 중 인공와우 사용자는 $\mathrm{S} 2, \mathrm{~S} 5, \mathrm{~S} 6$ 이었고 나머지는 보청기 사용자였다.

\section{건청인과 청각장애인의 $\mathrm{VO}$ 및 $\mathrm{AV}$ 제시 조건에 따른 문장인지도} 수행력 비교

$\mathrm{VO}$ 와 $\mathrm{AV}$ 조건별 건청인과 청각장애인 간 수행력을 비교하기 위 해 $t$-test를 실시한 결과(Figure 1$),+10 \mathrm{~dB}$ 조건( $t=-1.208, p>.05)$ 에 서는 두 그룹 간 차이가 없었으나 $\mathrm{VO}$ 조건 $(t=-6.627, p<.001)$ 과 +5 $\mathrm{dB}$ 조건 $(t=-5.518, p<.001)$ 에서는 청각장애인의 수행력이 유의미 하게 높았으며, $+15 \mathrm{~dB}$ 조건 $(t=3.813, p<.001)$ 에서는 건청인의 수 행력이 유의미하게 높은 것으로 나타났다.

\section{논의 및 결론}

본 연구에서 한국표준 일반용 문장표(Jang et al., 2008b)의 VO 조건 하 목록 간 난이도의 동등성을 확인한 것은 $\mathrm{AO}$ 조건 하에 어 음청력검사용으로 개발되어 있는 기존의 도구를 독화능력검사에 활용하기 위한 기초 정보를 확인하기 위한 것이었다. 한국표준 일 반용 문장표의 발화 영상을 제작하여 건청 성인을 대상으로 $\mathrm{VO}$ 조
건에서 문장인지도를 측정한 결과, 건청인의 전체 평균 문장인지도 가 $\mathrm{VO}$ 조건에서 $14.24 \%, \mathrm{AV}$ 조건에서 최대 $93.07 \%$ 로 나타나 시각 단서만으로는 말인지에 상당한 어려움을 겪는 것으로 나타났으며, 이러한 결과는 청각 단서가 말인지에 미치는 영향이 시각 단서에 비해 현저히 큼을 시사한다. 맥락적인 단서가 문장 내 단어인지도 독화수행력에 미치는 영향을 보고하는 연구들이 다수 있으며(Grant \& Seitz, 2000; Lansing \& Helgeson, 1995; Marslen-Wilson, Moss, \& van Halen, 1996; Rönnberg, et al., 1998), 특히 VO 조건에서 문 장인지 수행력을 측정한 연구들(Altieri, Pisoni, \& Townsend, 2011; Altieri \& Hudock, 2014; Tye-Murray, Sommers, \& Spehar, 2007)에 서 보고한 바닥효과(floor effect)가 본 연구결과에서도 동일하게 나타났다. 즉 $\mathrm{VO}$ 조건만으로는 문장의 맥락적 단서를 활용하는 데 제한이 있었다.

문장인지도 검사는 목표단어 정반응률을 기준으로 실질적인 어 음인지능력을 측정하므로 이를 기준으로 문장 목록의 점수를 살 펴 본 결과, $14.69 \%-32.11 \%$ 로 목록 간 유의미한 차이를 보이는 것으 로 나타났다. 통계적으로 $16.64 \%-20.63 \%$ 에서 시각적 문장인지도 검사의 동등성이 확인되었으며 이러한 목록은 목록 $1(20.63 \% \pm$ $15.58 \%)$, 목록 $3(16.64 \% \pm 12.17 \%)$, 목록 $4(20.00 \% \pm 16.45 \%)$, 목 록 $6(18.67 \% \pm 17.32 \%)$ 이었다. 이러한 결과는 실험II에서 다른 건청 인 그룹과 청각장애인 그룹을 대상으로 실시한 VO 조건에서의 점 수에서도 목록 간 차이를 보이지 않아 동등성에 대한 타당성이 지 지됨을 알 수 있다. 그러므로 한국표준 일반용 문장표를 $\mathrm{VO}$ 조건과 $\mathrm{AV}$ 조건으로 실시하는 경우, 이러한 4 개 목록의 사용이 권장된다.

본 연구의 또 다른 목적은 동등성이 검증된 목록을 사용하여 $\mathrm{VO}$ 및 $\mathrm{AV}$ 조건에서 건청인과 청각장애인의 문장인지도를 비교함 으로써 청각장애인의 시각 및 청각 정보 활용 정도를 살펴보고자 하였다. 먼저, 난이도의 동등성이 확인된 4 개의 목록을 사용하여 $\mathrm{AV}$ 제시 조건에 따른 건청 성인의 수행력을 확인한 결과, $\mathrm{VO}$ 조건 에서 $14.24 \%$ 이던 것이, 청각 정보를 $5 \mathrm{~dB} \mathrm{SL}$ 에서 $15 \mathrm{~dB}$ SL까지 올렸 을 때, 점수가 $42.80 \%$ 에서 $93.07 \%$ 까지 높아져 청각 정보량이 많아 질수록 수행력이 향상되는 것으로 나타났다. 이는 검사도구의 표 준화 연구(Jang et al., 2008b)에서 제시하는 $\mathrm{AO}$ 조건에서 제시 강 도별 수행력 즉, $5 \mathrm{~dB} \mathrm{HL}$ 에서 $48.08 \%, 10 \mathrm{~dB} \mathrm{HL}$ 에서 $85.70 \%, 15 \mathrm{~dB}$ $\mathrm{HL}$ 에서 $97.90 \%$ 로 본 연구의 결과와 거의 유사한 점수를 보여 건청 인의 경우 청각 자극에 높은 의존도를 보이는 것으로 나타났다. 또 한 $\mathrm{AV}, \mathrm{AO}, \mathrm{VO}$ 검사가 모두 포함된 CUNY Sentence를 본 연구와 동일하게 문장의 목표단어 정반응 수를 백분율로 구하여 청시각 통합 능력을 평가한 연구(Altieri \& Hudock, 2014)와도 유사한 수 행력을 나타내었다. 해당 연구에서 VO 조건에서는 $14.30 \%$, 편안한 
강도에서 청각 정보를 제시한 $\mathrm{AV}$ 조건에서는 $94.70 \%$ 의 수행력을 보였다.

본 연구에서 청각장애인 또한 청각 정보를 $5 \mathrm{~dB}$ SL에서 $15 \mathrm{~dB} \mathrm{SL}$ 까지 높이면서 제시했을 때, 4 개 전체 목록의 평균이 $32.24 \%$ 에서 $82.56 \%$ 까지 상승하여 청각 정보량이 증가할수록 더 높은 수행력 을 나타내었다. 그러나 청각 정보가 포함된 각 $\mathrm{AV}$ 조건에서 4 개의 목록 간 유의미한 차이를 보여 청각장애인이 청각 정보를 활용하 는 능력에 개인차가 있음을 나타내었다. 소리의 크기가 $\mathrm{AV}$ 조건에 서 수행도에 미치는 영향은 청각장애인이 보장구 착용으로 얻는 이득을 반영하며, 청각장애인의 의사소통에서 잔존청력이 가지는 중요성을 시사한다. 보장구 또는 음향적인 정보와 관련된 독화의 이점에 대한 선행연구를 살펴보면, Sommers 등(2005)은 청각장애 인의 잔존청력이 많을수록 독화 수행도도 좋아진다고 하였으며, Grant 등(2013) 은 고주파수 잔존청력이 있는 청각장애인이 독화 에서 보완적인 정보를 얻을 수 있다고 하였고, 이에 더하여 Tye-Murray (2014)는 입술과 턱의 움직임이 말소리의 저주파수보다는 고주 파수와 더 연관이 있기 때문에 저주파수 손실이 있더라도 중주파 수와 고주파수 잔존청력이 있는 사람은 시각 정보의 기여도가 더 클 수 있음을 언급하였다. 또한 보장구를 통한 소리의 크기(음압 및 강도 수준, 진폭 엔벨로프)와 기본주파수 등의 초분절적 특성들은 정도의 차이는 있지만 독화 수행에 이득을 주며(Bosman \& Smoorenburg, 1997; Dahlquist, 1989; Faulkner, Ball, Rosen, Moore, \& Fourcin, 1992; Grant et al., 1998), 청각장애인이 인공와우 사용에 서 얻는 큰 이익 중 하나가 독화가 수월해지는 것으로 보고되었다 (Brown \& Bacon, 2009). 더하여 AV 조건에서의 단어와 문장 단위 의 자극에 대한 독화 수행도는 청각 및 시각적 단서를 통한 상향식 처리만 아니라 어휘 및 구문론, 의미론적 분석에 의한 하향식 처리 에도 영향을 받는 것으로 보고되고 있다(Grant \& Seitz, 1998, 2000; Grant et al., 1998).

본 연구에 참여한 청각장애인 11 명의 $\mathrm{AV}, \mathrm{VO}, \mathrm{AO}$ 조건에서의 수 행력을 청각과 시각 통합에 따른 향상도(integration enhancement) 모델(Tye-Murray, 2014)을 적용하여 살펴볼 때, 인공와우 사용자 는 예측된 점수보다 평균 $17.43 \%$, 보청기 사용자는 $32.05 \%$ 더 높은 것으로 나타났다. 본 연구에 참여한 청각장애인 집단으로 한정할 때, $\mathrm{AO}$ 조건에서 수행도가 높은 2 명의 대상자를 제외하고 모든 대 상자가 한 가지 감각에서보다 청시각이 통합되는 경우에서 더 많은 이득을 얻는 것을 확인하였다. 본 연구에 참여한 보청기 대상자의 경우 모두 고심도 난청이었으며, 보청기를 사용한 상태에서도 $\mathrm{AO}$ 조건에서 $0 \%$ 의 인지도와 $\mathrm{VO}$ 조건에서 $23.13 \%-53.75 \%$ 를 보였지만 청시각이 통합된 $\mathrm{AV}$ 조건에서 $78.75 \%-100 \%$ 로 높은 수행력을 보였
다. 이러한 특성은 인공와우 사용 대상자에게도 동일하게 나타났 으므로 이는 청각장애인이 문장 인지를 위해 단일 감각이 아닌 청 시각 모두를 활용하며 이 과정에서 상당한 이득을 얻는 것으로 나 타났다. 이러한 결과는 선행연구를 통해서도 지지되는데 Dorman, Hannley, Dankowski, Smith와 McCandless (1989)은 평균 10년 이 상의 고심도 난청으로 인공와우를 착용하고 있는 대상자에게 CID Everyday Sentences 검사를 $\mathrm{AO}, \mathrm{VO}, \mathrm{AV}$ 조건에서 시행하여 $\mathrm{AO}$ 조 건의 수행력보다 $\mathrm{VO}, \mathrm{AV}$ 조건에서 수행력이 더 좋음을 확인하였 고, 청시각이 통합되었을 경우 문장인지도의 수행력이 월등하게 상승함을 보였다. 그러나 주된 이득을 얻는 감각 양식이 대상자가 착용하는 보장구의 종류 또는 청력손실의 정도 및 유형과 관련이 있는 것인지, 아니면 단순히 개인차에서 기인하는 것인지에 대하여 향후 통계적으로 유의미한 결과를 얻기에 충분한 인원수의 청각장 애인을 대상으로 확인해 볼 필요가 있을 것이다.

건청인 21 명과 청각장애인 11 명을 대상으로 두 집단 간 $\mathrm{VO}$ 와 $\mathrm{AV}$ 제시 조건하에 수행력을 비교할 때, $\mathrm{VO}$ 와 청각 신호 $+5 \mathrm{~dB} \mathrm{SL}$ 제시 조건에서 청각장애인의 수행력이 건청인보다 유의미하게 높았으 며, $+15 \mathrm{~dB}$ SL 제시 조건에선 건청인이 청각장애인에 비해 유의미하 게 높은 수행력을 나타내었다. 이 검사 결과는 $\mathrm{VO}$ 조건에서 건청인 은 $18.57 \% \pm 13.18 \%$, 청각장애인은 $43.55 \% \pm 17.48 \%$ 의 수행력을 보인 이전 연구(Auer \& Bernstein, 2007)와 유사한 결과로 청각장 애인은 건청인보다 시각적 어음 정보에 의존도가 더 높으며(Bernstein, Tucker, \& Demorest, 2000), 청각 정보와 함께 독화능력을 향 상시키는 것으로 나타났다(Grant \& Seitz, 1998). Bernstein 등(2000) 은 청각장애인 집단과 건청인 집단 모두 $\mathrm{VO}$ 조건에서 낮은 수행도 를 보였지만 청각장애인 대다수가 건청인보다 수행도가 높았으며, 특히 심도의 선천성 난청의 수행력이 가장 높았음을 보고하였다. 그러므로 후속연구에서 청각장애인의 청력손실 정도, 유형(Altieri \& Hudock, 2014) 및 난청 기간(Dorman et al., 1989) 등의 요인들에 따른 독화능력을 확인할 필요가 있다. 본 연구에서 KS-SL의 목록 간 동등성을 검증하여 독화능력 검사에 활용함으로써 추후 독화 능력 검사도구의 개발 가능성을 확인하였으며, 이를 기반으로 임 상에서 청각장애인이 시각 정보와 청각 정보를 종합하여 의사소통 능력을 최대화할 수 있는 방향으로 독화 훈련을 실시하는 방안도 고려할 수 있을 것이다.

\section{REFERENCES}

Altieri, N. A., Pisoni, D. B., \& Townsend, J. T. (2011). Some normative data on lip-reading skills (L). The Journal of the Acoustical Society of America, 
130(1), 1-4.

Altieri, N., \& Hudock, D. (2014). Assessing variability in audiovisual speech integration skills using capacity and accuracy measures. International Journal of Audiology, 53(10), 710-718.

American Speech-Language-Hearing Association. (1988). Determining threshold level for speech. Retrieved from http://doi.org/0.1044/policy. GL1988-00008

Arnold, P., \& Hill, F. (2001). Bisensory augmentation: a speechreading advantage when speech is clearly audible and intact. British Journal of Psychology, 92(2), 339-355.

Auer, E. T., \& Bernstein, L. E. (2007). Enhanced visual speech perception in individuals with early-onset hearing impairment. Journal of Speech, Language, and Hearing Research, 50(5), 1157-1165.

Bergeson, T. R., \& Pisoni, D. B. (2004). Audiovisual speech perception in deaf adults and children following cochlear implantation. In G. A. Calvert (Ed.), The handbook of multisensory processes (pp. 749-771). Cambridge, MA: MIT Press.

Bernstein, L. E., Tucker, P. E., \& Demorest, M. E. (2000). Speech perception without hearing. Perception \& Psychophysics, 62(2), 233-252.

Bosman, A. J., \& Smoorenburg, G. F. (1997). Speechreading supplemented with auditorily presented speech elements in the profoundly hearing impaired. Audiology, 36(1), 29-45.

Brown, C. A., \& Bacon, S. P. (2009). Achieving electric-acoustic benefit with a modulated tone. Ear and hearing, 30(5), 489-493.

Calhoun, G. L., Janson, W. P., \& Valencia, G. (1988). Effectiveness of threedimensional auditory directional cues. Proceedings of the Human Factors Society Annual Meeting, 32(2), 68-72.

Choi, J., Yoon, K., Ryu, H., \& Jang, H. (2017). Analysis of Korean viseme system in Korean standard monosyllabic word Lists. Communication Sciences \& Disorders, 22(3), 615-628.

Dahlquist, M. (1989). Comparison between two methods of extracting supplemental information for speechreading. Speech Transmission Laboratory Quarterly Progress and Status Report, 30(1), 151-154.

Dancer, J., Krain, M., Thompson, C., \& Davis, P. (1994). A cross-sectional investigation of speechreading in adults: effects of age, gender, practice, and education. The Volta Review, 96(1), 31-40.

Davis, H., \& Silverman, S. R. (1970). Hearing and deafness. New York, NY: Holt, Rinehart \& Winston.

Dodd, B. (1977). The role of vision in the perception of speech. Perception, 6(1), 31-40.
Dorman, M. F., Hannley, M. T., Dankowski, K., Smith, L., \& McCandless, G. (1989). Word recognition by 50 patients fitted with the Symbion multichannel cochlear implant. Ear and Hearing, 10(1), 44-49.

Faulkner, A., Ball, V., Rosen, S., Moore, B. C., \& Fourcin, A. (1992). Speech pattern hearing aids for the profoundly hearing impaired: speech perception and auditory abilities. The Journal of the Acoustical Society of America, 91(4), 2136-2155.

Gaylor, J. M., Raman, G., Chung, M., Lee, J., Rao, M., Lau, J., \& Poe, D. S. (2013). Cochlear implantation in adults: a systematic review and meta-analysis. JAMA Otolaryngology-Head \& Neck Surgery, 139(3), 265-272.

Geers, A., \& Brenner, C. (1994). Speech perception results: audition and lipreading enhancement. The Volta Review, 96(5), 97-108.

Geers, A., Brenner, C., \& Davidson, L. (2003). Factors associated with development of speech perception skills in children implanted by age five. Ear and Hearing, 24(1), 24S-35S.

Grant, K.W., Bernstein, J. G., \& Summers, V. (2013). Predicting speech intelligibility by individual hearing-impaired listeners: the path forward. Journal of the American Academy of Audiology, 24, 329-336.

Grant, K. W., \& Seitz, P. F. (1998). Measures of auditory-visual integration in nonsense syllables and sentences. The Journal of the Acoustical Society of America, 104(4), 2438-2450.

Grant, K. W., \& Seitz, P. F. (2000). The use of visible speech cues for improving auditory detection of spoken sentences. The Journal of the Acoustical Society of America, 108(3), 1197-1208.

Grant, K. W., Walden, B. E., \& Seitz, P. F. (1998). Auditory-visual speech recognition by hearing-impaired subjects: consonant recognition, sentence recognition, and auditory-visual integration. The Journal of the Acoustical Society of America, 103(5), 2677-2690.

Jang, H., Lee, J., Lim, D., Jeon, A., \& Hyun, J. (2008a). Development of Korean standard sentence lists for preschoolers used in sentence recognition test. Audiology, 4(2), 178-187.

Jang, H., Lee, J., Lim, D., Lee, K., Jeon, A., \& Jung, E. (2008b). Development of Korean standard sentence lists for sentence recognition tests. Audiology, 4(2), 161-177.

Lansing, C. R., \& Helgeson, C. L. (1995). Priming the visual recognition of spoken words. Journal of Speech, Language, and Hearing Research, 38(6), 1377-1386.

Marslen-Wilson, W., Moss, H. E., \& van Halen, S. (1996). Perceptual distance and competition in lexical access. Journal of Experimental Psychology: Human Perception and Performance, 22(6), 1376-1392. 
McGurk, H., \& Macdonald, J. (1976). Hearing lips and seeing voices. Nature, 264, 746-748.

Oliveira, L. N. D., Soares, A. D., \& Chiari, B. M. (2014). Speechreading as a communication mediator. CoDAS (Sociedade Brasileira de Fonoaudiologia), 26(1), 53-60.

Oxenham, A. J., \& Kreft, H. A. (2014). Speech perception in tones and noise via cochlear implants reveals influence of spectral resolution on temporal processing. Trends in Hearing. https://doi.org/10.1177/2331216514553783

Park, H. J., Han, S. A., Choi, J. H., Sim, S. Y., Seo, Y. R., Jang, H. S., ... \& Seo, Y. R. (2016). The relationship between vocabulary knowledge and speech perception in school-age children using cochlear implants. Communication Sciences \& Disorders, 21(3), 488-501.

Rönnberg, J., Andersson, J., Andersson, U., Johansson, K., Lyxell, B., \& Samuelsson, S. (1998). Cognition as a bridge between signal and dialogue: communication in the hearing impaired and deaf. Scandinavian Audiology, 27(4), 101-108.

Sommers, M. S., Tye-Murray, N., \& Spehar, B. (2005). Auditory-visual speech perception and auditory-visual enhancement in normal-hearing younger and older adults. Ear and hearing, 26(3), 263-275.

Strelnikov, K., Rouger, J., Lagleyre, S., Fraysse, B., Démonet, J. F., Déguine, O., \& Barone, P. (2015). Increased audiovisual integration in cochlear-implanted deaf patients: independent components analysis of longitudinal positron emission tomography data. European Journal of Neuroscience, 41(5), 677-685.

Tye-Murray, N. (2014). Foundations of aural rehabilitation: children, adults, and their family members. Stamford, CT: Cengage learning.

Tye-Murray, N., Sommers, M. S., \& Spehar, B. (2007). Audiovisual integration and lipreading abilities of older adults with normal and impaired hearing. Ear and Hearing, 28(5), 656-668.

Wilson, S., Dancer, J., \& Stamper, J. (1984). Visual equivalency of Harris' Revised CID Everyday Sentence Lists. The Volta Review, 86(6), 267-273.

Woll, B. (2012). Speechreading revisited. Deafness \& Education International, 14(1), 16-21. 


\section{국문초록}

\section{건청인과 청각장애인의 시각 및 청시각 제시조건에서 문장인지도 비교 곽종현 $\cdot$ 최재희 ${ }^{\prime}$ 장현숙 ${ }^{2}$}

1한림대학교 일반대학원 언어병리청각학과, ${ }^{2}$ 한림대학교 언어청각학부 및 청각언어연구소

배경 및 목적: 건청인과 청각장애인 모두 의사소통에서 청각과 시각 단서를 활용하고 있으나, 청각장애인의 실질적 의사소통능력을 측 정하기 위해서는 청각 조건(AO)뿐만 아니라 청시각 조건(AV)에서도 어음인지도를 측정할 필요가 있다. 본 연구는 한국표준 일반용 문 장표(KS-SL-A) 목록 간 시각적 난이도의 동등성을 확인하고, 이를 바탕으로 $\mathrm{VO}$ 및 $\mathrm{AV}$ 조건에서 건청인과 청각장애인의 문장인지도 를 비교하였다. 방법: 남녀 화자의 KS-SL-A 발화 영상을 제작하고, 32 명의 건청인에게 VO 조건에서의 문장인지도를 검사하여 8 개 목 록 간 난이도의 동등성을 확인하였다. 동등성이 확인된 목록을 사용하여 21 명의 건청인과 11 명의 청각장애인을 대상으로 $\mathrm{VO}$ 및 $\mathrm{AV}$ $(5,10,15 \mathrm{~dB} \mathrm{SL})$ 조건에서 집단 간, 제시조건 간 문장인지 수행력을 비교하였다. 결과: $\mathrm{VO}$ 조건에서 문장인지도를 측정한 결과, KS-SL$\mathrm{A}$ 목록 8 개 중 $1,3,4,6$ 간 유의한 차이가 없었다. 시각적 난이도의 동등성을 확인한 목록 4 개를 사용하여 $\mathrm{AV}$ 조건에서 청각정보의 제 시강도를 $15 \mathrm{~dB}$ SL까지 높였을 때 건청인과 청각장애인 그룹 모두 문장인지도가 증가하였으나, $\mathrm{VO}$ 및 $5 \mathrm{~dB}$ SL에서 청각장애인이 건청 인보다, $15 \mathrm{~dB}$ SL에서 건청인이 청각장애인보다 유의하게 높은 수행력을 보였다. 논의 및 결론: 청각장애인은 건청인에 비해 시각적 정 보를 크게 활용하고 있으며, 청각정보가 추가되었을 때 독화능력이 최대화되므로 실생활 속 의사소통능력에 대한 정보를 얻기 위해 추 후 임상연구에서는 $\mathrm{AO}$ 조건과 $\mathrm{AV}$ 조건에서 청각장애인의 어음인지를 평가할 필요가 있다.

핵심어: 청각장애인, 한국표준 문장표, 문장인지도, 시각 제시조건, 청시각 제시조건, 목록 간 동등성

본 연구는 한림대학교 교비연구비 지원을 받아 수행하였음(No. HRF-201708-007).

\section{참고문헌}

박혜진, 한성아, 최재희, 심상용, 서영란, 장현숙(2016). 학령기 인공와우 아동의 어휘력과 말지각 간의 상관성. Communication Sciences \& Disorders, 21(3), 488-501.

장현숙, 이정학, 임덕환, 이경원, 전아름, 정은조(2008b). 문장인지검사를 위한 한국표준 문장표 개발. 청능재활, 4(2), 161-177. 장현숙, 이정학, 임덕환, 전아름, 현재환(2008a). 문장인지검사를 위한 학령전기용 한국표준 문장표 개발. 청능재활, 4(2), 178-187.

최재희, 윤건석, 류혜수, 장현숙(2017). 한국표준 단음절어표를 이용한 한국어 독화소체계 분석. Communication Sciences \& Disorders, 22(3), 615-628.

\section{ORCID}

곽종현(제1저자, https://orcid.org/0000-0003-1298-1435); 최재희(공동저자, https://orcid.org/0000-0002-1446-2797); 장현숙(교신저자, https://orcid.org/0000-0001-5496-8218) 